ISSN:2528-9527

E-ISSN : 2528-9535

YIl Year: 8

Cilt Volume: 8

Sayı Issue : 15

\title{
Türkiye'de E-Ticaret Sektörünün Yıllara Göre Gelişimi
}

\author{
DOI: $10.26466 / o p u s .453147$
}

\section{Mehmet Demirdöğmez ${ }^{*}$ Nihat Gültekin ${ }^{* *} \underline{\text { H. Yunus Taș }}{ }^{* * *}$}

* Öğr. Gör., Harran Üniversitesi, Birecik Meslek Yüksek Okulu, Şanlıurfa/Türkiye E-Posta: mdemirdogmez@harran.edu.tr ORCID: $0000-0002-4412-5943$

**Doç. Dr., Harran Üniversitesi, İktisadi ve İdari Bilimler Fakültesi , Şanlıurfa /Türkiye E-Posta: nihat@harran.edu.tr ORCID: 0000-0001-6692-1628

${ }^{* * *}$ Doç. Dr., Yalova Üniversitesi, İktisadi ve İdari Bilimler Fakültesi, Yalova/Türkiye E-Posta: yunus.tas@yalova.edu.tr

ORCID: $\underline{0000-0003-3163-9416}$

\section{Öz}

Teknolojinin gelişimiyle birlikte bilgi teknolojileri de hızlı bir gelişim gösterdi. İnternetin hayatımıza girmesinden sonra E-ticarette bu gelişimden payını aldı ve hızlı bir şekilde büyüdü. Öyle ki bazı ülkelerde ana sektörlerden biri haline geldi. E-ticaret pazarı dünya da olduğu gibi ülkemizde de hızla büyüyor. Ülkemizdeki bu büyümenin nedenleri arasında, Türkiye'de satın alma gücünün artarak Avrupa seviyesine ulaşması ve buna bağh olarak kişisel harcamaların artması. Dolayısılla e-ticaret pazarının büyümesinin en önemli nedenlerinin başında, yaygın internet kullanımının olduğu söylenebilir. Türkiye'de, nüfusun \%67'sine tekabül eden 54 Milyon internet kullanicıs var ve bunların 51 Milyonu telefonlarından internete bağlanıyorlar. Öte yandan Türkiye'deki nüfusun \%67'si, yani yaklaşık 54 Milyon internet kullanıcısının çok büyük bir kısmının kredi kartı kullanıcısı olması, e-ticaretin büyümesine katkı sağlayan dĭger önemli bir faktör olarak değerlendirilebilir. Türkiye'de 2018 Mart sonu itibariyle 63 milyon adet kredi kartı, 135 milyon adet banka kartı olmak üzere, toplam 198 milyon adet kart sayısına ulaşılmıştır. 2018 yılının ilk üç aylık döneminde kredi kartlarıyla yapılan alışverişler \%17 oranında artış göstermiş̧ir. Bu çalışmanın amacı E-ticaretin Türkiye açsindan yıllar itibariyle gelişmesini, özellikle son on yıl içerisindeki kazandığı ivmeyi gözler önüne sermektir. Çalışmamızın kaynakları, ikincil veriler ve bu konuda yapılan ve yıllar itibariyle açıklanan gerek kamu gerekse özel şirketlerin raporları olacaktır. Özellikle TÜIK, TÜBİSAD, DELOİTTE ve BKM verileri önemli oranda katkı să̆layacaktır. Çalışmamızın temelini rakamlar oluşturduğundan içerikte birçok tablo ve şekil kullanılacaktır.

Anahtar Kelimeler:E-ticaret, İnternet, alışveriş, ticaret, satış

OPUS @ Uluslararası Toplum Araştırmaları Dergisi-International Journal of Society Researches ISSN:2528-9527 E-ISSN : 2528-9535

http://opusjournal.net 


\title{
Development of E-Commerce Sector In Turkey By Years
}

\begin{abstract}
With the development of technology, the information technology has also showed rapid development. After the network got into our lives in, e-commerce has also share its part and grew rapidly. It grew so fast even it became one of the main sectors in some countries. E-commerce market is growing rapidly in our country as well as around the world. Among the reasons for this growth in our country, the increase the purchasing power and reach to the level of European in Turkey and depending that the increase in personal expends. Therefore, it can be said that one of the most important reasons for the growth of e-commerce market is widespread network use. On the other hand, \%67 of Turkey's population, ie approximately 54 million network users of a large portion have credit card, that contribute to the growth of e-commerce can be regarded as an another important factor. The aim of this study is to unfold the development of e-commerce over the years for Turkey that the momentum gained especially in the last decade. The sources of our study will be secondary data, held and released as the years both public and private reports. In particular TÜIK, TÜBISAD, DELOITTE, EUROMONITOR and BKM(ICC) data will contribute significantly. That the basis of the study basis on figures, in the content there will be used many tables and graphics.
\end{abstract}

Keywords: E-commerce, Internet, shopping, trade, sales 


\section{Giriş}

Türkiye'de "e-ticaret sektörü", çok hızla büyüyen sektörlerden birisi, aslında bu durum tüm dünya için de aynı. Bunun sebepleri arasında insanların internetten alışveriş yapma alışkanlıkları kazanmalarının yanısıra, e-ticaret sitesi işletmelerinin de işlerini gelişmiş araçlarla ve daha iyi bir biçimde yapmaları sayılabilir. Kuzey Amerika ve Asya-Pasifik, Dünya çapında en yüksek e-ticaret hacmine sahip bölgeler. Bu bölgeler e-ticarette oldukları gibi, geleneksel ticaret konusunda da büyük bir ticaret hacmine sahipler. Tabi ki güçlü ekonomileri sayesinde bu seviyeyi yakalamışlar. Ancak işin ilginç olan tarafı bu bölgelere göre dünyanın diğer kısımlarında, e-ticaretin daha hızla büyümesi. Türkiye'nin de içerisinde bulunduğu bazı ülkeler son zamanlarda e-ticaretin en fazla ivme kazandığ1 bölgeler olarak görünüyor. E-ticaret, özellikle ülkemiz gibi hıla büyüyen ekonomilere, birçok avantaj sunuyor (ideasoft,www.eticaretmag.com).

E-ticaret'in büyümesine ve gelişmesine katkı sağlayan pek çok unsur bulunmaktadır. Bu unsurların başlıcaları, nüfus büyüklüğü, internet kullanım oranı, gelişen ve artan alternatif ödeme sistemleri, gelişmiş lojistik destek sistemleri şeklinde sayılabilir. Bütün bunlarla birlikte, genç nüfus oranımızın büyüklüğü, yeni teknolojilere daha kolay ve hızlı adapte olmamıza imkân tanıyor böylece e-ticaret ve başka bilgi teknolojileri hızla gelişiyor. Başka bir sebepte lojistik destek sistemleri ve bankacılık sektörünün ülkemizde daha fazla gelişmiş olmasıdır. Günümüzde birçok kargo firması çok kısa sürelerde gönderileri bize teslim eder konumdalar.başka bir sebep te Türk toplumu olarak kredi kartını çok sevmemiz gösterilebilir( www.melihguney.com) Türkiye 81 milyon nüfusa sahip bir ülke olmasına rağmen nüfusunun \%67'si yani 54.3 milyon internet kullanıcısı var, nüfusunun \%51'i yani yaklaşık 41 milyon sosyal medya kullanıcısı var ve nüfusunun $\% 54$ 'ü yani hemen hemen 44 milyon mobil sosyal medya kullanıcısı var (www.dijilopedi.com). 


\section{Türkiye'de İnternet Kullanım Oranları}

ODTÜ ve TÜBİTAK'ın 25 yıl önce başlattıkları ve Ülkemizin de bir ucundan bağlandığı internet, bugün sadece bir "proje" olmaktan çıkıp sosyal ve ekonomik hayatımızda hemen her alana girmiş, kalkınma ve büyümenin temel altyapılarından birisi haline gelmiş, neredeyse ekmek-su gibi temel ihtiyaçlarımızın arasına girmiştir. Türkiye'deki gelişim sürecinde internet kullanan kişi sayısı 25 yılda 54,3 milyon kişiye ulaşmıştır. İnternetin yıllar içindeki gelişimi rakamlarla ifade edilecek olursa; 2008 yılı itibariyle yaklaşık 6 milyon olan geniş bant internet abone sayısı, 2017 yılı sonunda bu rakam 68,9 milyon seviyesine ulaşmıştır. 2009 yılının temmuz ayında kullanılmaya başlanan mobil geniş bant hizmeti, mobil bilgisayarlar ve cep telefonu internet abonesi sayısı 2017 yılı sonu itibariyle 57 milyona yaklaşmıştır. 2017 yılında da internet abonesi sayısındaki artış devam etmiş ve toplam internet abone sayısının yıllık artış oranı $\% 10,6$ olarak gerçekleşmiştir (www.ticarihayat.com.tr). Türkiye İstatistik Kurumu (TÜİK), 2017 yılı için gerçekleştirdiği Hanehalkı Bilişim Teknolojileri Kullanım Araştırması'nı tamamlayarak internet sitesinde yayınlamıştır. TÜİK' in bu raporunda, Türkiye' deki internet kullanım oranları ve e-ticaret gibi birçok konuda veriler sunulmaktadır.

\subsection{5-2017 TÜİK Girişimlerde Bilişim Teknolojileri Kullanım veri- lerine göre;}

TÜİK'in araştırma sonuçlarına göre; 2016 yılında \%93,7 olan 10 ve daha fazla çalışana sahip girişimlerin "internete erişim oranı" 2017 yılında \%95,9 olarak tespit edilmiştir. Çalışan sayısının büyüklük oranlarına göre internet erişim oranları ise; 10-49 çalışana sahip girişimlerde \%95,4, 50-249 çalışana sahip girişimlerde $\% 97,8,250$ ve üzeri çalışana sahip girişimlerde ise \%99,7 olmuştur. 10 ve daha fazla çalışana sahip girişimler için "bilgisayar kullanım oranı" 2016 yılında \%95,9 iken 2017 yılında bu oran \%97,2 ye yükselmiştir. Girişimler bir önceki yıl \%66 oranında web sayfasına sahip iken, 2017 yılında bu oran \%72,9'u bulmuştur. "Web sayfasına sahiplik" oranında \%87 ile ilk sıralarda 250 ve üzeri çalışana sahip olan girişimler yer alırken, bunları \%82,1 ile 50-249 çalışana sahip girişimler ve 
\%70,5 ile 10-49 çalışana sahip girişimler takip etmiş. 2017 yılında girişimlerin \%94,2'si internete erişimde genişbant bağlantı kullanmış.

Girişimlerde bilgisayar kullanımı, İnternet erişimi ve web sayfası sahipliği, 2005$2017\left(^{*}\right)$

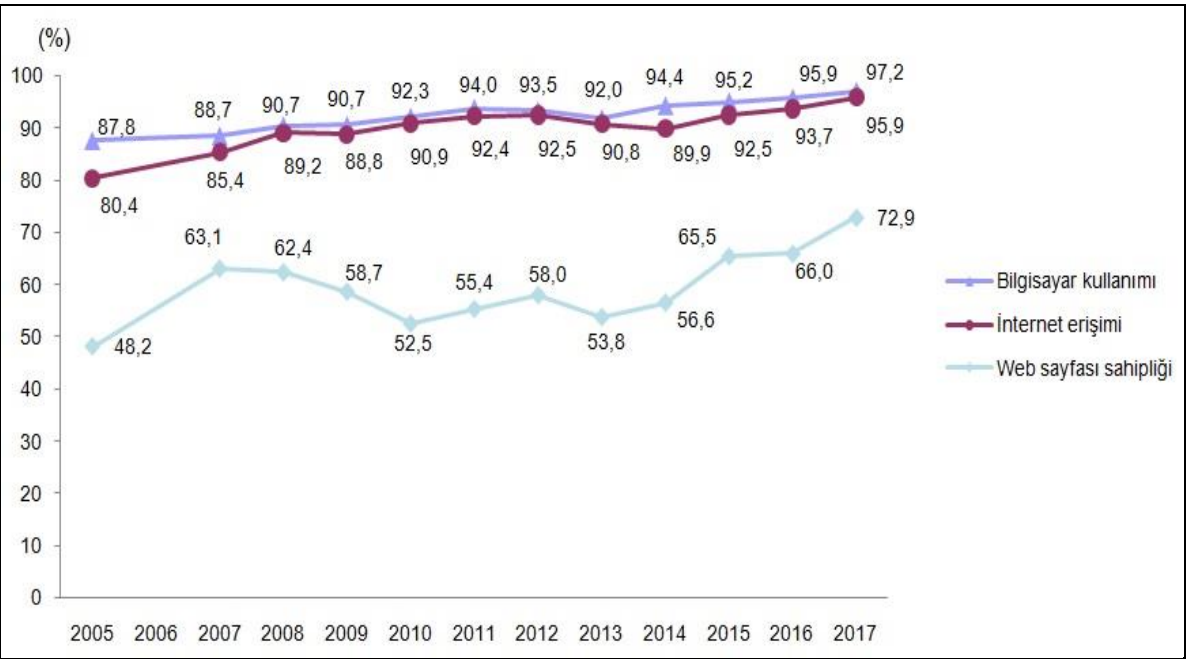

Kaynak: TÜİK, Girişimlerde Bilişim Teknolojileri Kullanım Araştırması, 2017

2016 'da toplam \%10,9 girişim internet ya da elektronik veri alışverişi (EDI) yoluyla alış veriş yapmış. Çalışan sayısına göre bu oran 250 ve üzeri çalışana sahip olan girişimlerde \%20,9, 50-249 çalışana sahip girişimlerde $\% 12,9$ ve $10-49$ çalışana sahip girişimlerde de $\% 10,1$ olmuş. Bu araştırmaya göre 10 ve daha fazla çalışana sahip olan girişimlerin 2016' da \%38,1'i, 2017 yılında \%45,7'si "sosyal medyayı" kullanmış. \%95,6 oranıla "sosyal ağlar", girişimlerin en çok tercih ettiği sosyal medya uygulaması olmuş. 2016 ' da girişimler, kamu kurum ve kuruluşları ile iletişimde $\% 86,2$ oranında interneti kullanmış. Bu girişimler interneti, \%91,3 oranında kamu kurum ve kuruluşlarından bilgi almak, $\% 78,1$ resmi form indirmek, $\% 73,2$ resmi formları doldurmak, $\% 53,5$ KDV beyannamesi vermek ve $\% 55,8$ ile SGK beyannamesi vermek amaciyla kullanmış. 


\subsection{8-2017 TÜİK Hanehalkı Bilişim Teknolojileri Kullanım Verile- rine Göre İse;}

2017 yılında, "Bilgisayar ve internet kullanım" oranı 16-74 yaş grubundaki kişilerde $\% 56,6$ ve $\% 66,8$ olmuş. 2016 'da bu oranlar $\% 54,9$ ve $\% 61,2$ şeklinde gerçekleşmiş. "Bilgisayar ve internet kullanım" oranları erkek bireylerde $16-74$ yaş grubunda $\% 65,7$ ve $\% 75,1$, bayanlarda $\% 47,7$ ve $\% 58,7$ olmuş. Bu araştırma sonuçlarına göre haneler, 2016 yılı Nisan ayında \%76,3'ü, 2017 yılı aynı ayında ise \%80,7'si “evden internete erişim" imkânına sahip olmuş.

Temel göstergeler, 2008-2017

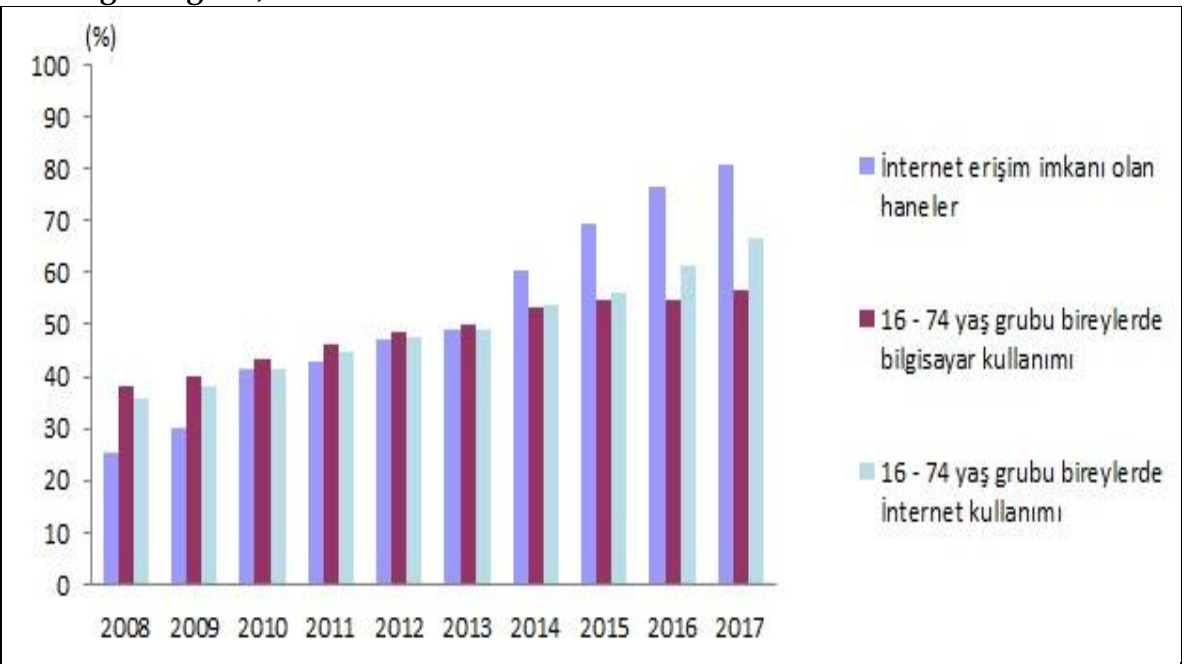

Kaynak: TÜİK, Hanehalkı Bilişim Teknolojileri Kullanım Araştırması, 2017

2017 yılı Nisan ayında "genişbant internet erişim" imkânına sahip hanelerin oranı \%78,3 olmuş. Bu oran bir önceki yıl \%73,1 oranında gerçekleşmiş.Hanelerin $\% 40$ ' 1 internete erişimini sabit genişbant bağlantı (ADSL, kablolu internet, fiber vb.) ile sağlarken, \%72,4'ü mobil genişbant bağlantı ile erişim sağlamış. Bireysel olarak kamu hizmetlerinden yararlanmak amacıyla 2016 yılı Nisan ile 2017 yılı Mart ayları arasındaki 12 aylık zamanda 16-74 yaş grubundaki kişiler interneti \%42,4 oranında kullanmış. Bir önceki yılın aynı döneminde bu oran \%36,7 olmuş. İnterneti kullanma amacı kamu kurumlarından “bilgi edinme” olanlar \%37,6 oranı 
ile ilk sırada yer almış. Alışveriş amacıyla interneti kullanan 16-74 yaş grubu bireylerin oranı $\% 24,9$, bir önceki yıl ise $\% 20,9$ olmuş.Internetten alışveriş yapan bireyler 2016 yılı Nisan ile 2017 yılı Mart ayları arasındaki 12 aylık zamanda \%62,3 oranında giyim ve spor malzemeleri, \%25,3 oranında ev eşyası (Tüketici elektroniği dışında, mobilya, oyuncak, beyaz eşya vb), \%24,1 seyahat hizmetleri, \%21,9 gıda ve günlük ihtiyaçlar ile \%19 oranında elektronik(Cep telefonu, kamera, radyo, TV vb.) satın almışlar.

\section{Türkiye'de E-Ticaretin Tarihçesi}

TÜBİTAK ve ODTÜ'nün çalışmaları neticesinde Türkiye'de internet var olmaya ve kullanılmaya başladı. 1991 yılında bu konudaki çalışmalar başladı ve 12 Nisan 1993 tarihinde Türkiye'de ilk internet bağlantısı gerçekleştirildi. İlk olarak ODTÜ'de internet kullanılmaya başladı. 1994 ve 1996 yılları arasında bu üniversiteyi, Bilkent, Boğaziçi, İstanbul ve Ege Üniversiteleri takip etti. Ardından Mynet, Ekşi Sözlük gibi özel internet siteleri de faaliyete başlamış oldu.

1997 yılında Bilim ve Teknoloji Yüksek Kurulu(BTYK), elektronik ticaret ağının oluşturulması amacıyla bir toplantı gerçekleştirdi ve böylece, e-ticaretin yolu açılmış oldu. Diş Ticaret Müsteşarlığına "koordinatörlük", TÜBİTAK'a ise "sekreterya" görevi verilmiştir. 1998 yılında Dış Ticaret Müsteşarlığı başkanlığında Elektronik Ticaret Koordinasyon Kurulu(ETKK) oluşturulmuştur. Bu kurul içerisinde finans, hukuk, teknik vb. gruplar çalışmalar yürütmüştür. Bilim ve Teknoloji Yüksek Kurulu Türkiye'de e-ticaretin geliştirilmesiyle ilgili; teknik ve idari alt yapı ile yasal ve hukuki alt yapının kurulması, e-ticareti özendirecek tedbirlerin alınması ve aynı zamanda ulusal politika ve uygulamaların uluslararası politika ve uygulamalarla uyumlu hale getirilmesi şeklinde görevler belirlemiştir.

Türkiye'de internetten daha fazla ve etkili bir biçimde yarar sağlamak için "e-Türkiye" adlı çalışma, 2001 yılında Başbakanlığın koordinasyonuyla gerçekleştirilen bir toplantı ile başlamış, DTM bünyesinde oluşturulan Elektronik Ticaret Genel Koordinatörlügü̈, "e-Ticaret çalışma grubu" olarak görevini sürdürmeye devam etmiştir. 2003 yılı başında, KOSGEB, Gümrük Müsteşarlığı ile Bankalar Birliği olmak üzere üç adet 
uygulama grubu ile çalışmalar sürdürülmüştür. E-ticaret çalışma grubu tarafından 2003-2004 yılı eylem planı hazırlanmıştır.

Diğer bir proje ise $\mathrm{AB}$ Komisyonunun uygulamakta olduğu Teknik Destek ve Bilgi Değişim Mekanizması (TAIEX)'dir. TAIEX, AB mevzuatının iç hukuka aktarılması, uygulanması ve faydalanıcı ülkelere uzman desteği sağlayan bir oluşumdur. 2007 yılında DTM koordinasyonunda e-ticaret uygulama grubunun üyeleri olan tüm kamu kurum ve kuruluşları ile birlikte hazırlanan TAIEX projesi, AB'nin e-ticaret alanındaki mevzuatını incelemek amacıyla hazırlanmış ve Komisyonca kabul edilmiştir.

Türkiye' de elektronik ticarete ilişkin kanuni düzenlemelerin olmaması nedeniyle 2008 yılında, DTM ve tüm diğer ilgili kamu kurum ve kuruluşlarının katkılarıyla "Elektronik Ticaret Direktifi Çalışma Grubu" teşkil edilmiştir. Çalışma grubu tarafından üretilmiş raporların değerlendirmesini müteakip, 2009 yılında e-ticaret kanunu hazırlanması amacıyla, AB hükümetler arası fonları kullanılarak, DTM tarafından geliştirilip, AB Komisyonuna sunulan ve kabul gören Hollanda-Türkiye hükümetleri arası (G2G), “AT Elektronik Ticaret Direktifine Uyum Sağlanması ve Direktifin Uygulanması için Destek" isimli Projesi Adalet Bakanlığ1 koordinasyonunda hayata geçirilmiştir. "e-Ticaret Kanunu Hazırlama Komisyonu" çalışmaları sonucunda, "Elektronik Ticaretin Düzenlenmesi Hakkında Kanun Tasarı Taslağı" hazırlanmıştır. 2010 yılında Komisyonca hazırlanan "Elektronik Ticaretin Düzenlenmesi Hakkında Kanun Tasarı Taslağı" Adalet Bakanlığınca TBMM'ne sunumu ardından, 2 yılı aşan bir sürede alt Komisyonlarca görüşülmüş, ancak zamanaşımı neticesinde kadük olmuştur. Daha sonra yasa tasarısı Adalet Bakanlığınca düzeltmeleri yapılarak yeniden TBMM'ne sunulmuş 2014 tarihinde kabul edilerek, 2015 yılında yürürlüğe girmiştir. 6563 Sayılı “Elektronik Ticaretin Düzenlenmesi Hakkında Kanun"un bir gereği olarak, e-ticaret hakkındaki tüm alt mevzuat çalışmaları ve kamu düzenlemeleri koordinasyonu için Gümrük ve Ticaret Bakanlığ görevlendirilmiştir. Bakanlık, "Ticari İletişim Ve Ticari Elektronik İletiler Hakkında Yönetmelik" ile "Elektronik Ticarette Hizmet Sağlayıcı ve Aracı Hizmet Sağlayıcılar Hakkında Yönetmelik" adlı iki yönetmelikle servis sağlayıcıların sorumluluklarını ve ticari iletilerin içeriklerini detaylandırılmıştır(www.ekonomi.gov.tr). 


\section{Türkiye E-Ticaret Perakende Pazar Büyüklüğü}

We Are Social ve Hootsuite tarafından hazırlanan 2018 Dijital raporuna göre Türkiye' deki internet kullanıcılarının \%56'sı son 1 ay içerisinde satın almayı düşündükleri bir ürünü veya hizmeti internette arattı, \%60'ı bir online perakende mağazasını ziyaret etti, \%43'ü online platformda bir ürün ya da hizmet satın aldı, \%30'u online satın alma işlemlerini laptop ya da masaüstü bilgisayarlar, \%30'u ise mobil telefonlar aracıllğ çekleştirdi.2018 e-ticaret istatistiklerine göre en çok harcama elektronik kategorisinde gerçekleşti. Elektroniği, moda ve güzellik ürünleri takip ederken en düşük harcama dijital müzik alanında yapıldı. Bir önceki yıla kıyasla en çok büyüyen e-ticaret sektörü \%20'lik artışla moda ve güzellik olurken en az artış \%9'luk oranla video oyunlar olarak raporland. E-ticarette tüketim mallarına yönelik harcamalar \%8 oranında arttı ve 31,7 milyon kişi tüketim malları alışverişini e-ticaret üzerinden gerçekleştirdi. Tüketim mallarının e-ticaret pazarındaki oranI ise \%15 artarak 5,7 milyar \$'a ulaştı.(We Are Social, karaman.gsb.gov.tr)

\section{Türkiye'de e-ticaret pazar büyüklüğü}

Kategori payları ve site sayıları

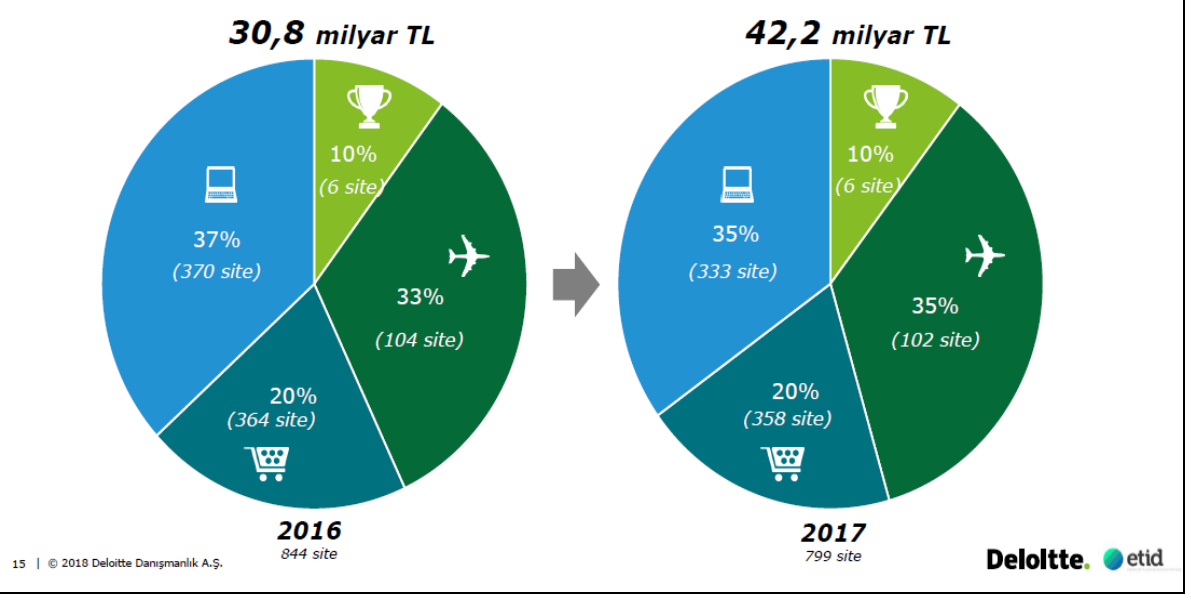

Kaynak:Tübisad,Etid,Deloitte Ortak Çalışması :Türkiyede E-Ticaret Pazar Büyüklü̆̆̈̈ Mayıs 2018 
Türkiye'de e-ticaret pazar büyüklüğü - kategoriler milyar TL

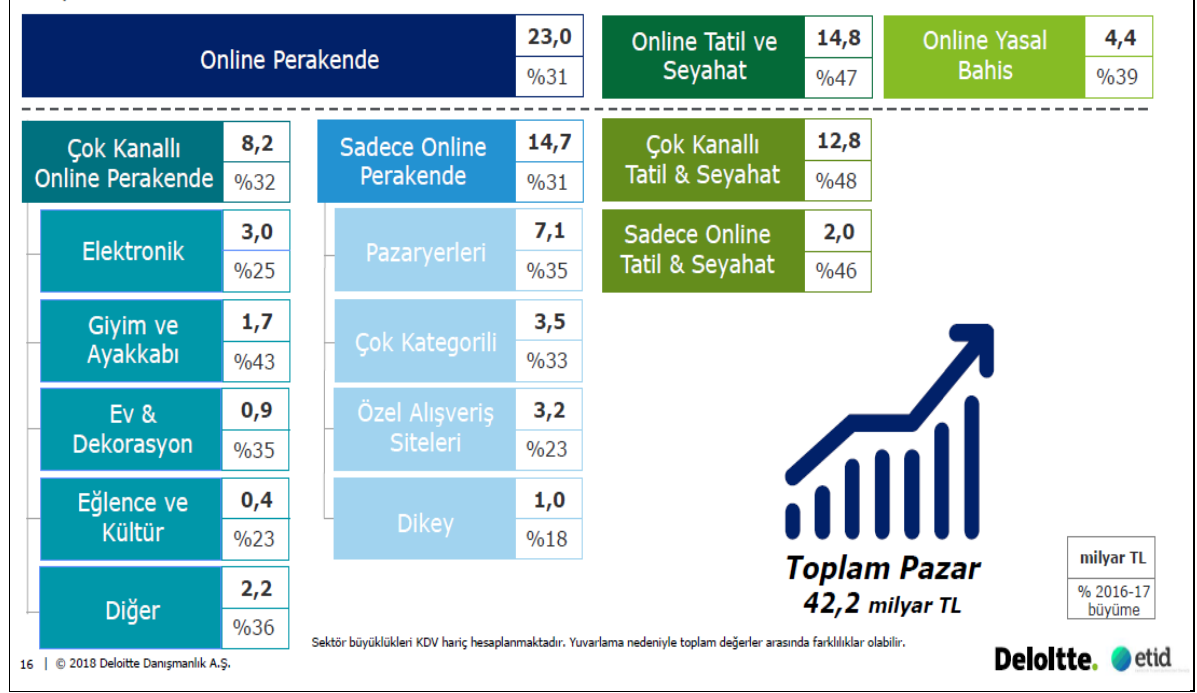

Türkiye İstatistik Kurumu TÜIK'in açıkladığı araştırma raporlarına göre, Türkiye ekonomisinde 2017 yılında \%7,4 büyüme gerçekleşti. 2018 yılı Mart ayında Tüketici Fiyat Endeksi bir önceki yılın aynı ayına göre \%10,23 oranında artış gösterdi. 2018 Mart ayı sonu itibarıyla Dolar 3,96 TL, Euro ise 4,88 TL oldu. Kredi kartıyla yapılan alışverişler 2018 yılının ilk üç ayında, geçen yılın aynı dönemine göre \%17 artış ile 160 Milyar TL , banka kartıyla yapılan alışverişler \%41 artış ile 20 milyar TL olmuş. Nakit çekim oranları, banka kartıyla gerçekleşen nakit çekim toplamı \%16 artış ile 159 milyar TL, kredi kartıyla gerçekleşen nakit tutarı \%3 artışla 18 milyar TL olmuştur. Toplam kredi kartı sayısı 63 milyon, banka kartı ise 135 milyon âdete ulaşmış. POS makinesi 1,6 milyon, ATM'ler ise 50 bin âdeti bulmuş. Temassiz kredi kartlarının payı \%40, temassız ödeme yapılabilen terminallerin oranı da $\% 40$ olarak gerçekleşmiş. Toplamda internetten kartla yapılan ödemelerin payı da \%16 olmuş. 


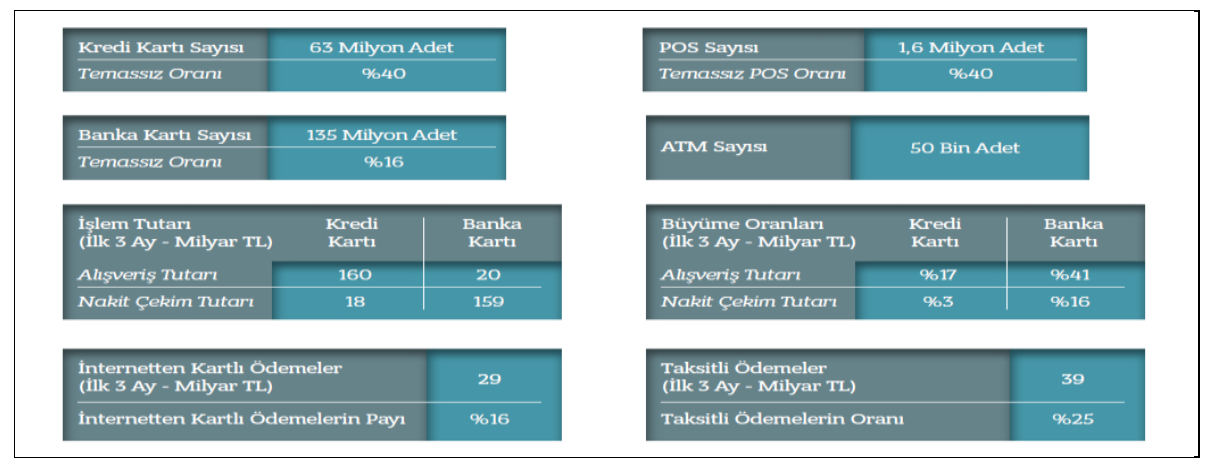

Kaynak: Bankalararası Kart Merkezi A.Ş. 1 Ocak - 31 Mart 2018 Ara Dönem Faaliyet Raporu

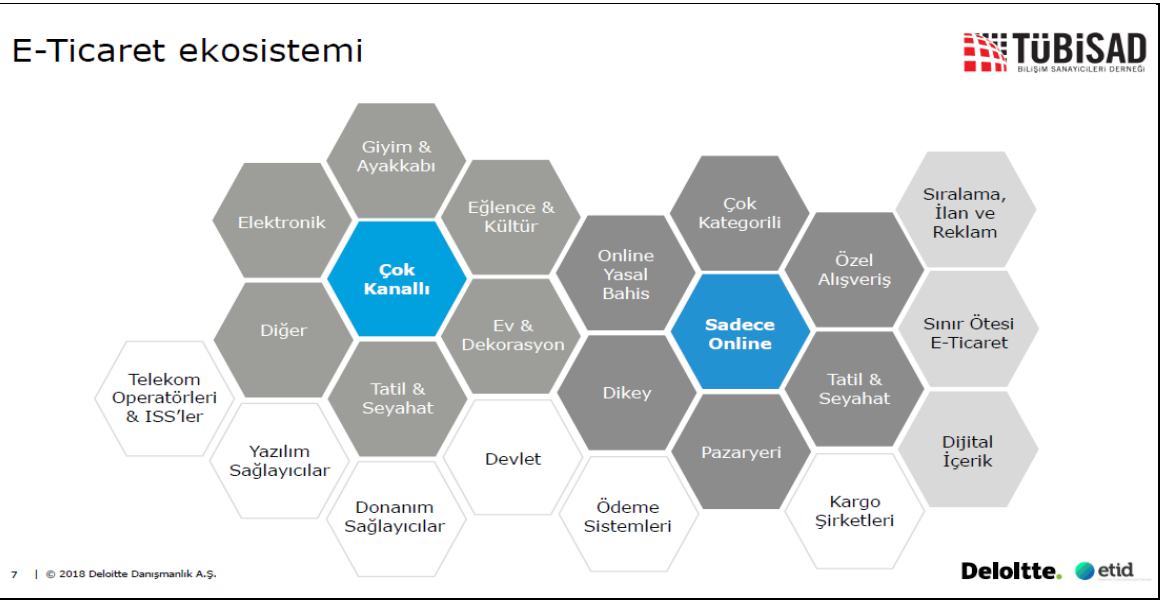

Kaynak:Tübisad,Etid,Deloitte Ortak Çalışması :Türkiyede E-Ticaret Pazar Büyüklüğü Mayıs 2018

\section{E-Ticaret Hacmini Etkileyebilecek Faktörler Ve Sektörlerde Yaşanan Sorunlar}

E-ticaret farklı faktörlerden etkilenebilmektedir. Her ülke de yapısına göre bu faktörlerden farklı biçimlerde etkilenmektedir. Ülkelerdeki iktisadi değişkenler ve internet alt yapısındaki gelişmeler, e-ticaret işlem hacmini doğrudan etkileyebilmektedir. Ayrıca, güçlü bir hukuki yapının oluşturulması e-ticaret hacmini arttıracağı, ekonomik krizlerin ise e-ticaret işlem 
hacmini olumsuz etkileyerek düşüreceği sanılmaktadır.(türen,gökmen,tokmak)

Sektörde yaşanan sorunlar

Çalışmamızı yürüttüğümüz dönem boyunca sektörün çözüm bekleyen sorunları pek değişmemiş,

'nitelikli iş gücủ açı̆ğı' ve 'fiyat odaklı dıs kaynak kullanımı/kamu ihale politikaları' bilișim

şirketlerimiz tarafından büyümeyi olumsuz etkenlerin başında gösterilmeye devam etmiştir

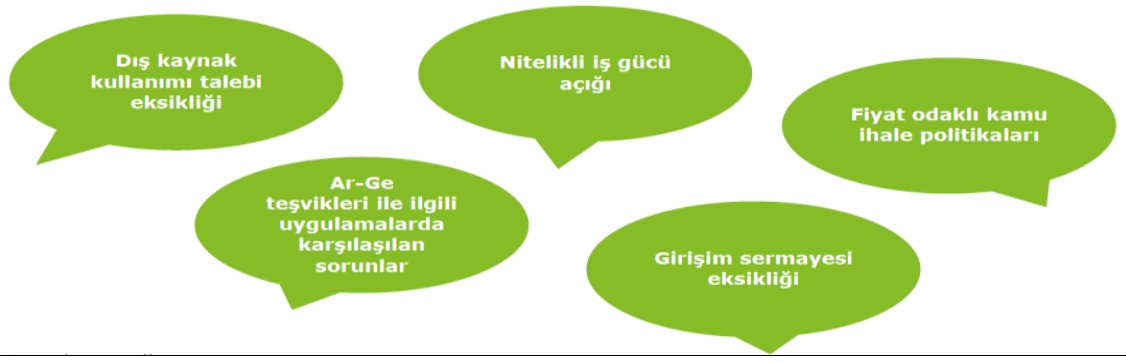

Kaynak: TÜBİSAD Bilgi ve İletişim Teknolojileri Sektörü 2017 Pazar Verileri-Mayıs 2018

Yukarıdaki tablodan da anlaşılacağı gibi Sektörel bazda yaşanan sorunlar şöyle siralanabilir.

- Nitelikli işgücü açıkları artarak devam ediyor.

- AR_GE teşvikleri uygulamalarındaki sorunlar çok az bir düşüş göstermesine rağmen hala devam ediyor.

- Siyasal yapılara bağlı olarak değişen fiyat odaklı kamu ihale politikalarındaki sorunlar

- Girişim sermayesi eksikliği düşüş gösteriyor bu iyi bir gelişme ancak yeterli değil.

- Üniversite ve sanayi işbirliğinin yetersizliği hala hissedilmekte.

\section{Gelecek Yıllarda E-Ticaret Sektöründe Neler Bekleniyor}

2018 yılının gelişi ile birlikte bir önceki yılın e-ticaret verilerini ortaya koyan yerel ve küresel ölçekli araştırmaların sonuçlarına dair tahminler doğrultusunda 2017 yılı 2. yarısı ve son çeyreğine dair rakamlar, e-ticaretin Türkiye'de yolları hızla kat ettiğini ortaya koyuyor. Üstelik birkaç yıl içinde Türkiye' de e-ticaretin toplam perakende içindeki payının çift haneli rakamlara ulaşacağına dair öngörüler de söz konusu. Örneğin Worldpay tarafından yürütülen ve yakın zamanda kamu ile paylaşılan 
küresel araştırma, Türkiye'nin Hollanda ve İtalya'dan sonra Avrupa'nın en hızlı büyüyen pazarı olduğunu gösteriyor. Araştırmanın sonuçlarına göre 2021 yılına kadar yıllık yüzde 13 oranında büyüme performansı göstermesi beklenen Türkiye'nin yalnızca yüzde 1 oran ile Hollanda ve İtalya'nın gerisinde kalacağı düşünülüyor(www.aa.com.tr)

Özellikle gençlerin ve çalışan kadınların yoğun katkılarıyla her yıl gelişme gösteren e-ticaret sektörü, 2018 yılında da yüzde 40 büyüme hedeflemektedir. 2017'de banka ve kredi kartı ile yapılan harcamalar yaklaşık \%35 artış göstermiş durumda. 2016 yılında 30,8 milyar TL'yi bulan e-ticaret pazar büyüklüğünün, aynı oranlarda artarak 40 milyar hatta 50 milyar lirayı aşacak tahminleri yapılıyor (www.pazarlamasyon.com)

Son 4 aylık verilere bakıldığında 2018 yılının da e-ticaret sektörü için yine yüzde 40 'lar mertebesinde bir büyüme ile başladığ1 söylenebilir. Rakamsal olarak bir iki yıl içinde, iki üç sene aralığında online perakendenin normal perakende içindeki yüzde 4,1'lik payının 6-8 aralığına gelmesi çok muhtemeldir. Temel ekonomik göstergelerde çok büyük bir şaşma olmazsa bundan sonra çok hızlı bir büyüme olacağı öngörülmektedir(www.timeturk.com) Tüketici satın alma davranışlarında köklü değişiklikler yapan e-ticaret sektörü, geleceği parlak bir sektör olarak görülüyor. Her şeyin daha da hızlandığı, elektronik cihazların küçülüp daha hafif ve rahatça taşınabilir hale geldiği günümüzdeki bu durumdan, e-ticaret büyük ölçüde etkilenecektir.

E-ticaretin alışverişlerde müşterisine pek çok seçenek sunması, gelecekte mağazaya giderek yapılan geleneksel alışverişi azaltacaktır. Yakın bir gelecekte "ses ile arama" özelliği e-ticaret sitelerinde boy gösterecektir. E-ticaret yapan işletmelerin uluslararası alanda da faaliyet göstermesi, çeşitli ülkelerdeki potansiyel müşterilere de ulaşabilmesi anlamını taşıyor. E-ihracat yakın gelecekte artış göstererek, pek çok firmanın ülke dışına da satış yapmak amacıyla kargo, web site altyapısı, yazılım vb. alanlarda düzenleme ve yeniliklere gitmek zorunluluğunda olacağı öngörülmektedir(www.xtrlarge.com). Dijital dönüşüm, perkende

pazryeri (retail marketplace) açısından çok ciddi fırsatlar sunmaktadır. Dijital dönüşüm, şirketlerin geleceği demektir. İşletmelerin dijital dönüşüme ayak uyduramaması ise e-ticaretin büyümesine engeldir. Yakın gelecekte pazaryeri mantığıyla faaliyet gösteren e-ticaret işletmeleri, 
yerini kendi mamüllerini doğrudan satan firmalara bırakacaklar diye düşünülmektedir(www.digitalage.com.tr).

\section{Sonuç ve Öneriler}

E-ticaret sektöründe bulunan potansiyeli hayata geçirebilmesi için e-ticarete ivme kazandırabileceği kanısını taşıdığımız konular aşağıda ana ve alt başlıklar halinde sunulmuştur.

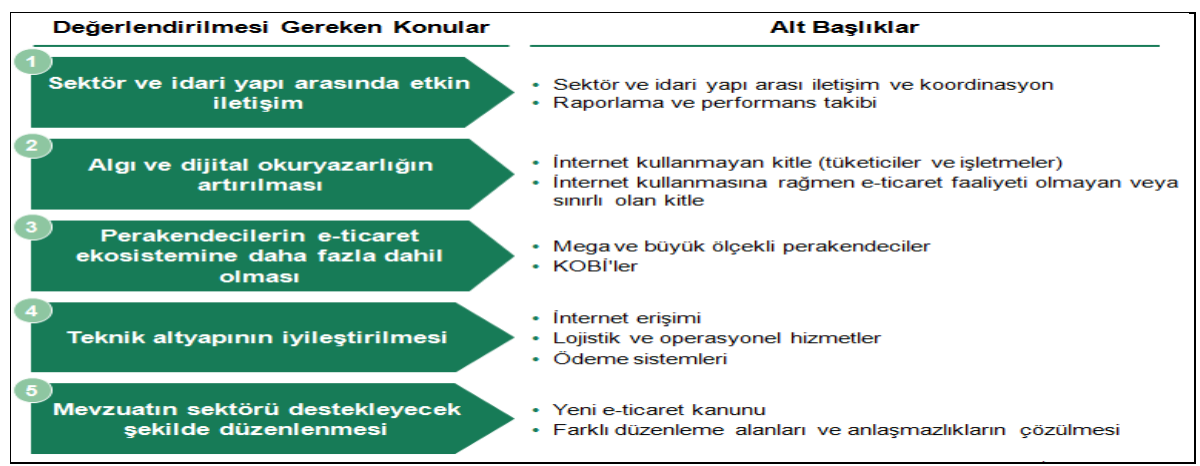

E-ticaret sektörü potansiyelini hayata geçirebilmesi için perakendecilerin ve KOBI'lerin e-ticaret ekosistemine dâhil olması gerekmektedir. Aynı zamanda, algı ve dijital altyapının iyileştirilmesi, sektör ve idari yapı arasında etkin iletişimin sağlanması önem arz etmektedir. Türkiye' nin e-ticaret potansiyelini tam anlamıyla etkinleştirebilmesi, ekonomisine ve ihracatına önemli katkılar sağlayacaktır.

\section{Yapılabilecekler için Öneriler}

İnterneti kullanan ancak alışveriş yapmayan veya sınırlı sayıda alışveriş yapanlar için;

- Kamu, sektör oyuncuları, bankalar, lojistik şirketleri vb. iştiraki ile Ülke genelinde e-ticarete ivme kazandırabilecek kampanyalar yapilabilir.

- Güven olgusunu artırmak için, ürünlerin iade sürecinin, kredi kartı harcama itirazı süreçlerinin müşteriye anlatılması.

- E-ticaretin güvenli olduğu vurgusu kamu spotları şeklinde sunulabilir. 
- Tüketiciler, e-ticaret işletmeleri ve devlet nezdinde farkındalık oluşturma şeklinde, dijital okuryazarlığın artırılması, algının pozitifleştirilmesi ve e-ticaretin müşterilere, ülke ekonomisine ve kamuya olan katkısı anlatılabilir.

İnterneti hiç kullanmamış bireyler için;

Devlet desteği sağlanarak "her eve internet" şeklinde yurt çapında bir faaliyet başlatılabilir.

- İnternet servis sağlayıcıları, yerel yönetimler ve devlet desteği ile şehir merkezlerinde veya toplu taşıma araçlarında ücretsiz internet hizmeti verilebilir.

- Akıllı telefonlar ve mobil internet paket fiyatlarındaki ÖTV oranları belirli müşteriler için düşürülebilir.

- Devletçe desteklenen ve özel sektör firmaları tarafından bilgi ve bilinç düzeyinin artırılması amacıyla sosyal sorumluluk projeleri düzenleyebilir.

Sabit ve mobil internet kullanımını arttırmak için:

- E-ticaret sektörü için kaldıraç vazifesini gören ve e-ticaret ekosisteminin altyapısını oluşturan yüksek hızlı genişbant uygulamasının teşvikinin sağlanması, sürecin kolaylaştırılması ve süreçteki mali yükümlülüklerin hafifletilmesi çalı̧̧malarına hız verilebilir.

- İletişim sektörünün mali yükümlülükleri hafifletilebilir.

- Elektronik cihazlara uygulanan vergiler azaltılarak genişbant kullanımının yaygınlaştırılması sağlanabilir.

- Fiber altyapı ve yaygınlaştırma çalışmalarına hız verilebilir.

- İnternet kullanım oranının düşük olduğu kesimlerde halkın internetle tanışmasını sağlayacak kampanyalar ile mobil abonesi olduğu halde internet kullanmayan tüketiciler için telefon ve internet kampanyaları yapılabilir.

Ürün teslimat süreçlerinin iyileştirilebilmesi için:

- Ürün iade süreçleri, müşterileri zorlamayacak şartsız ve ücretsiz biçimde işletilmelidir. Müşteriye güven verecek iade süreçleri tasarlanmalı, hasarlı ürünlerin anında iadesi için, lojistik ve operasyonel süreçlere de standartlar getirilmelidir. 
- Ücretsiz kargo, e-ticaret işletmelerince bir değer önerisi olarak tüketiciye sunulmalıdır.

- Müşterilerin kargo durumlarını takip edebilmelerine imkân verilmelidir.

Sektördeki ödeme sisteminin eksiksiz işlemesi ve müşteride güven oluşması için:

- Güçlü şifreleme ve güvenlik yöntemleri (TLS, web sertifika kullanımı vb.) 3-D secure süreçleri yaygınlaştırılarak ödeme süreçleri de standardize edilmelidir.

- Kredi kartı ile ödeme dişında alternatif ödeme sistemleri çeşitlendirilmeli, kapıda ödeme gibi alternatifler sunulmalıdır.

- Kredi kartlarıyla ilgili harcama itiraz başvuru süreçleri ile ilgili müşteriler daha net bilgilendirilmelidir.

- E-ihracata destek olmak için mevcut ödeme sistemlerinin entegrasyonu sağlanmalıdır.

Mevcut sürecin ve mevzuat hükümlerinin tüketici ve işletmelerin haklarını daha iyi gözetebilmesi için:

- Sektör ile idari yapı arasındaki sağlıklı iletişim ve görüş alışverişi, sektör ihtiyaçlarının idari yapı tarafında daha net anlaşılmasını ve daha hızlı adımlar atılmasını sağlayabilir. Öte yandan, bilgi güvenliği gibi konularda, özellikle tüketicileri koruma amacıyla çeşitli önlemler hayata geçirilirken, sektöre olan olumlu ve olumsuz etkilerinin geniş bir çerçevede değerlendirilmesi gerekmektedir.

- Elektronik Ticaretin Düzenlenmesi Hakkında Kanun'un kapsamı, uyuşmazlık ve çelişkili durumlara mahal vermeyecek şekilde genişletilebilir.

- E-ticaret sektörünün yeni girişimlere destek verecek şekilde canlı tutulması sağlanabilir.

- Dolandırıcılı̆̆ın engellenmesi için sektördeki işletmelerin, BKM'deki kara liste bilgilerinin tutulduğu Birleşik Uyarı Listesine (BUL)'a erişimin sağlanması için adımlar atılabilir. Öte yandan, sektördeki işletmelerin kendi veri tabanlarındaki kara liste bilgilerini paylaşabilecekleri bir platform oluşturulabilir. 
Sonuç olarak, yapılan araştırmalarda da görüldügü gibi Türkiye' de ve dünya da internet kullanımı artarak devam ediyor. Bu durumda internetten alışveriş yapmak için son derece uygun şartların doğmasını sağlıyor. 


\title{
EXTENDED ABSTRACT
}

\section{Development of E-Commerce Sector in Turkey by Years}

\author{
Mehmet Demirdöğmez - Nihat Gültekin - H. Yunus Taş
}

Harran University / Yalova University

With the development of technology, the information technology has also showed rapid development. After the network got into our lives in, e-commerce has also share its part and grew rapidly.It grew so fast even it became one of the main sectors in some countries. E-commerce market is growing rapidly in our country as well as around the world. Among the reasons for this growth in our country, the increase the purchasing power and reach to the level of European in Turkey and depending that the increase in personal expends. Therefore, it can be said that one of the most important reasons for the growth of e-commerce market is widespread network use. On the other hand, \%67 of Turkey's population, ie approximately 54 million network users of a large portion have credit card, that contribute to the growth of e-commerce can be regarded as an another important factor. The aim of this study is to unfold the development of ecommerce over the years for Turkey that the momentum gained especially in the last decade.

For those who use the internet but do not shop or do a limited number of shopping;

- Public, sector players, banks, logistics companies and so on. campaigns that can accelerate e-commerce throughout the country.

- To increase confidence, tell the customer about the return period of products, credit card spending objections.

- The emphasis that e-commerce is safe can be presented as public spots.

- Increasing digital literacy, positive attitude and e-commerce contribution to customers, the country's economy and the public can 
be explained in the form of consumers, e-commerce operations and state awareness building.

For individuals who have never used the internet;

- State support can be provided to start a nation-wide activity in the form of "every home internet".

- Internet service providers, local governments and government support can provide free internet service in city centers or on public transport.

- SCT rates on smartphones and mobile internet package prices can be lowered for certain customers.

- State sponsored and private sector firms can organize social responsibility projects in order to increase the level of knowledge and awareness.

To increase the use of fixed and mobile internet:

- Speeding up efforts to provide incentives for high-speed broadband applications that see leverage for the ecommerce industry and constitute the infrastructure of the ecommerce ecosystem, facilitate the process and mitigate the financial burden on the process.

- The financial obligations of the communication sector can be mitigated.

- By reducing the taxation on electronic devices, it is possible to spread the use of broadband.

- Fiber infrastructure and dissemination efforts can be accelerated.

- Campaigns that enable people to meet the internet in areas where the internet usage rate is low and phone and internet campaigns can be made for consumers who do not use the internet even though they have mobile subscribers.

In order to improve product delivery processes:

- The product return processes must be operated in an unconditional and free format that will not force the customer. Customers should design reliable return processes, standardize the logistics and operational processes for immediate recovery of damaged products.

- Free shipping should be offered to consumers as a value proposition for e-commerce businesses. 
- Customers should be able to track their cargo status.

For the complete transaction of the payment system in the sector and for the establishment of trust in the customer:

- Strong encryption and security methods (TLS, web certificate usage, etc.) 3-D secure processes should be extended and payment processes standardized.

- Alternative payment systems other than credit card payment should be diversified and payment alternatives should be offered at the door.

- Customers should be more clearly informed about the spending appeal process for credit cards.

- Integration of existing payment systems must be provided to support e-export.

In order for the current process and legislative provisions to better monitor the rights of consumers and businesses:

- Healthy communication and exchange of views between the sector and the administrative structure can lead to a clearer understanding of the sectoral needs of the sector and faster steps to be taken. On the other hand, while various safeguards, such as information security, are used to protect consumers, various positive and negative effects of the sector need to be evaluated on a broad framework.

- The scope of the Act on the Regulation of Electronic Commerce can be extended to the extent that it does not give rise to disputes and contradictory situations.

- The e-commerce industry can be kept alive to support new initiatives.

- Steps can be taken to ensure that businesses in the sector have access to the Unified Alert List (BUL) where the black list information in the BKM is kept in order to prevent fraud. On the other hand, a platform can be created in which sectoral enterprises can share their blacklist information in their databases.

The sources of our study will be secondary data, held and released as the years both public and private reports. In particular TÜIK, TÜBISAD,DELOITTE, EUROMONITOR and BKM(ICC) data will contribute 
significantly. That the basis of the study basis on figures, in the content there will be used many tables and graphics.

\section{Kaynakça / References}

Bankalar arası Kart Merkezi A.Ş. 1 Ocak - 31 Mart 2018 Ara Dönem Faaliyet Raporu

Koçak, O. (2004). Elektronik ticaret ve çalışma hayatına etkisi. Yayınlanmamış Doktora Tezi, İstanbul Üniversitesi, Sosyal Bilimlerler Enstitüsü, İstanbul.

Koçak, O. (2011). Bilgi toplumu sürecinde çalışma yaşamı dijital teknolojiler boyutuyla. Bursa: Ekin Yayınları.

Koçak, O. (2009), Bilgi teknolojilerini kullanan yeni girişimcilik modelinin iş yaratma etkisi. Sosyal Siyaset Konferansları Dergisi, 57, 381-405

TÜBİSAD, ETID, DELOİTTE Ortak Çalışması: Türkiye'de E-Ticaret Pazar Büyüklüğü Mayıs 2018

TÜBİSAD Bilgi ve İletişim Teknolojileri Sektörü 2017 Pazar Verileri-Mayıs 2018

TÜIK, Girişimlerde Bilişim Teknolojileri Kullanım Araştırması, 2017

TÜIK, Hanehalkı Bilişim Teknolojileri Kullanım Araştırması, 2017

Türen, Ufuk, Gökmen, Yunus, Tokmak, İsmail ,Türkiye'de E-Ticaret İşlem Hacmini Etkileyen Faktörler Üzerine Bir Araştırma: Bir Model Önerisi

www.eticaret.com/blog/dunyada-ve-turkiyede-e-ticaret-pazari-ve-sizibekleyen-firsatlar/

www.melihguney.com/turkiyede-ve-dunyada-e-ticaretin-dunu-bugunuve-yarini.html

www.ekonomi.gov.tr/portal/content/conn/UCM/path/Contribution\%20Folders/web/Hizmet\%20Ticareti/Elektronik\%20Ticaret/BTS-e-devlet-giris-02_12_2015.pdf?lve

www.dijilopedi.com/2018-turkiye-internet-kullanim-ve-sosyal-medya-istatistikleri/ Wearesocial ve Hootsuit : "Digital in 2018 in Western Asia" raporu

www.ticarihayat.com.tr/haber/Turkiye-de-Internetin-25-Yili/16670 
www.ekonomi.gov.tr/portal/content/conn/UCM/path/Contribution\%20Folders/web/Hizmet\%20Ticareti/Elektronik\%20Ticaret/T\%C3\%B-Crkiyede\%20e-ticaret $\% 20$ tarih\%C3\%A7esi\%20devam $\%$ C4\%B1.-pdf?lve

www.karaman.gsb.gov.tr/Public/Edit/images/IM/47/Sosyal $\% 20$ Medya $\% 20$ ve $\% 20 \%$ C4\%B0nternet $\% 20 \mathrm{Kul}-$ lan\%C4\%B1m\%20Raporu.pdf

www.aa.com.tr/tr/ekonomi/e-ticaret-hacminde-2018-hedefi-50-milyarlira-/1070467

www.pazarlamasyon.com/e-ticaret/e-ticaret-2018de-\%40-buyume-hedefliyor/www.timeturk.com/e-ticaret-2018-e-yuzde-40-lar-mertebesinde-buyume-ile-basladi/haber-902034

www.xtrlarge.com/2018/01/04/e-ticaret-2018-populer-trend/www.digitalage.com.tr/e-ticaret-sektoru-yil-yuzde-30-buyuyor/

\section{Kaynakça Bilgisi / Citation Information}

Demirdöğmez, M., Gültekin, N. ve Taş, H. Y.(2018). Türkiye' de E-Ticaret sektörünün yıllara göre gelişimi. OPUS-Uluslararası Toplum Araştırmalarn Dergisi, 8(15), 2216-2236. DOI: 10.26466/opus.453147 